\title{
Diagnosis of Resistant Hypertension
}

\author{
M Khan ${ }^{1}$, S S Islam ${ }^{2}$
}

\begin{abstract}
Hypertension is a major risk factor of cardiovascular death in Bangladesh and worldwide. Resistant hypertension as well as uncontrolled hypertension with 3 or more antihypertensive agents is increasingly common in clinical practice. Clinicians should exclude pseudoresistant hypertension, which results from nonadherence to medications or from elevated blood pressure related to the white coat syndrome. Resistant hypertension may be associated with secondary causes of hypertension including obstructive sleep apnea or primary aldosteronism.
\end{abstract}

Northern International Medical College Journal Vol. 8 No. 01 July 2016, Page 196-198

1Dr. Moniruzzaman Khan Medical Officer (AD)

Bangladesh Bank, Barisal.

${ }^{2}$ Sharif Shaila Islam Asst. Surgeon Chakhar Union Health \& Family Welfare Center Banaripara, Barisal

Correspondence

Dr. Moniruzzaman Khan Medical Officer (AD)

Bangladesh Bank, Barisal. e-mail: dr.zaman1987@yahoo.com

\section{Introduction}

According to the seventh Joint National Committee (JNC-7), resistant hypertension is defined as the inability to achieve a blood pressure lower than 140/90 mm $\mathrm{Hg}$ despite optimal doses of 3 or more antihypertensive drugs, including 1 diuretic. ${ }^{1}$ Resistant hypertension is defined by American Heart Association (AHA) in 2008 as uncontrolled hypertension despite treatment with at least 3 antihypertensive drugs or controlled hypertension with at least 4 drugs. $^{2}$

Resistant hypertension is associated with increased cardiovascular disease ${ }^{3}$ and with emotional stress. ${ }^{4}$ The pathogenesis of resistant hypertension is unknown but appears to be multifactorial. Epidemiological studies demonstrate that older age, obesity, impaired renal function, and diabetes mellitus are all associated with resistant hypertension. ${ }^{5,6}$ Patients with resistant hypertension typically have elevated systemic vascular resistance and expanded plasma volume in the presence of normal cardiac output. ${ }^{7}$ Mechanisms underlying this abnormal hemodynamic pattern are unknown, but minor elevation in the circulating aldosterone levels and suppression of plasma renin activity have been identified in the majority of patients with resistant hypertension. 7,8

\section{Diagnosis}

\section{Evaluating Patients for the White Coat Syndrome and Pseudohypertension}

Before diagnosing resistant hypertension, clinicians must exclude medication nonadherence and the white coat syndrome. Isolated elevation of office blood pressure despite normal home blood pressure or 24-hour ambulatory blood pressure is common during treatment with antihypertensive medications and may lead clinicians to incorrectly diagnose patients as having resistant hypertension. A recent study estimated that the prevalence of white coat syndrome (defined as office blood pressure of $>140 / 90 \mathrm{~mm} \mathrm{Hg}$ or higher but normal 24-hour ambulatory blood pressure of $130 / 80 \mathrm{~mm} \mathrm{Hg}$ ) to be as high as $30 \%$ among patients with elevated office blood pressure despite treatment with at least 3 drugs. ${ }^{9}$ In multiple population studies, individuals with a white coat effect had fewer cardiovascular events than those with resistant hypertension and similar rates of cardiovascular events compared with patients with well controlled hypertension. ${ }^{10}$ However, the prognosis of hypertensive patients with white coat syndrome is worse than that of the general normotensive population. ${ }^{11}$ Continued home blood pressure or repeated ambulatory blood pressure monitoring 
is advisable for patients with white coat syndrome because between $20 \%$ and $25 \%$ of these patients may develop true resistant hypertension (uncontrolled office and 24-hour blood pressure while taking $>3$ or more drugs) within 3 to 6 months of follow-up. ${ }^{12}$

Nonadherence to antihypertensive medications is another cause of pseudoresistant hypertension. Adherence can be monitored with patient self-report, pill counts, or prescription refill rates. Self- report tends to overestimate adherence to antihypertensive medications by as much as $80 \%$ compared with electronic monitoring of pillboxes (which record the date and time of bottle openings). ${ }^{13}$ Similarly, pill counts are accurate in determining adherence in only $50 \%$ to $70 \%$ of patients compared with electronic pillboxes. ${ }^{14,15}$ Prevalence of medication nonadherence among patients with presumed resistant hypertension was $8 \%$ to $40 \%$ in the studies using questionnaires or pharmacy refill data. ${ }^{5}$ The prevalence of medication nonadherence was $50 \%$ to $60 \%$ when the more sensitive technique of therapeutic drug monitoring in the serum samples was used. ${ }^{16}$ Thus, physicians caring for patients with resistant hypertension should be highly vigilant regarding medication nonadherence. Once medication nonadherence is established, every effort should be made to identify barriers to medication adherence. These barriers may include adverse effects to antihypertensive drugs, excessively complex drug regimens, financial limitations, or patient cognitive dysfunction. ${ }^{17} \mathrm{~A}$ plan for improved adherence should be developed in partnership with each patient according to his/her specific situation.

\section{Secondary Causes in Resistant Hypertension}

Secondary hypertension is detected in $5 \%$ to $10 \%$ of all patients with hypertension. ${ }^{1,18}$ Obstructive sleep apnea is observed in $30 \%$ to $40 \%$ of patients with hypertension ${ }^{19}$ and in $60 \%$ to $70 \%$ of patients with resistant hypertension. ${ }^{20}$ Primary aldosteronism is present in $5 \%$ to $10 \%$ of all patients with hypertension and in $7 \%$ to $20 \%$ of patients with resistant hypertension. ${ }^{21-22}$

\section{A. Primary Aldosteronism}

Screening tests for primary aldosteronism include measuring plasma renin activity and serum aldosterone levels. These tests can be performed while patients are taking most antihypertensive drugs, but mineralocorticoid receptor antagonists and direct renin inhibitors should be stopped before these measures. However, a confirmatory assessment with an intravenous saline suppression test, to identify the presence of insuppressible aldosterone production after sodium loading, should be performed 2 to 3 weeks after discontinuing diuretics, angiotensin converting enzyme inhibitors, and angiotensin II receptor blockers and 4 to 6 weeks after discontinuing mineralocorticoid receptor antagonists. Patients who are found to have suppressed renin levels in the presence of elevated serum aldosterone levels ( $>15 \mathrm{ng} / \mathrm{dL}$ ) should undergo an intravenous saline suppression test (intravenous infusion of saline of $2 \mathrm{~L}$ over4 hours) or other confirmatory tests recommended by the Endocrine Society. ${ }^{23}$ Patients with insuppressible aldosterone levels of $10 \mathrm{ng} / \mathrm{dL}$ or more after the intravenous saline suppression test should undergo adrenal vein sampling. Patients with bilateral aldosterone overproduction should be treated with spironolactone or eplerenone. ${ }^{24}$ Patients with a unilateral tumor should undergo surgical removal of the adenoma, which has been shown to cure hypertension in $50 \%$ to $60 \%$ of patients. ${ }^{25}$

\section{B. Obstructive Sleep Apnea:}

In contrast to primary aldosteronism, clinical trials have shown that treatment of obstructive sleep apnea with continuous positive airway pressure (CPAP) resulted in modest blood pressure reductions in patients with resistant hypertension approximating 3 to $5 \mathrm{~mm} \mathrm{Hg}$. ${ }^{26}$ However, greater blood pressure reductions of 7 to $10 \mathrm{~mm} \mathrm{Hg}$ were reported in patients with resistant hypertension who regularly adhered to the CPAP treatment. ${ }^{26}$

\section{Renal Artery Stenosis:}

Renal artery stenosis is another common cause of secondary hypertension, identified in $2 \%$ to $24 \%$ of patients with resistant hypertension. ${ }^{20}$ There was no improvement in cardiovascular or renal outcomes compared with optimal medical therapy alone in atherosclerotic renal artery stenosis. Revascularization remains a treatment option for hypertension related to fibromuscular dysplasia. ${ }^{27}$ In addition, a recent large observational study suggested revascularization was beneficial when compared with medical therapy in reducing blood pressure in patients with resistant hypertension with atherosclerotic renal artery stenosis experiencing a rapid decline in renal function. ${ }^{28}$ However; prospective randomized studies are needed to confirm these findings.

\section{Other Causes:}

Hormonal testing to exclude other endocrine forms of hypertension such as pheochromocytoma, Cushing syndrome, or thyrotoxicosis should be performed when indicated based on clinical presentation. Certain substances or drugs, including oral 
contraceptives, are associated with resistant hypertension. ${ }^{20}$ Thus, a thorough history of prescription and nonprescription drug use, which may interfere with the efficacy of antihypertensive medications or directly increase blood pressure, should be obtained.

\section{Conclusion}

Resistant hypertension, particularly in patients who are already prescribed 3 or more drugs. Therefore in this cases selection of blood pressure lowering agents should be based not only on the antihypertensive efficacy but also on the incremental cost, the drugs' adverse effects, and their potential cardiovascular benefits. Optimization of antihypertensive regimen should be performed prior to extensive investigation for secondary hypertension along with non-pharmacological managementsodium intake, physical activity, substance abuse etc.

\section{References}

1. Chobanian AV, Bakris GL, Black HR, et al. National Heart, Lung, and Blood Institute Joint National Committee on Prevention, Detection, Evaluation, and Treatment of High Blood Pressure; National High Blood Pressure Education Program Coordinating Committee. The Seventh Report of the Joint National Committee on Prevention, Detection, Evaluation, and Treatment of High Blood Pressure: the JNC 7 report. JAMA. 2003; 289(19): 2560-2572.

2. Calhoun DA, Jones D, Textor $S$, et al. American Heart Association Professional Education Committee. Resistant hypertension: diagnosis, evaluation, and treatment. Circulation. 2008; 117 (25):e510-e526.

3. Kumbhani DJ, Steg PG, Cannon $C P$, et al. REACH Registry Investigators. Resistant hypertension: a frequent and ominous finding among hypertensive patients with atherothrombosis. Eur Heart J. 2013; 34(16):1204-1214.

4. Schmieder RE, Grassi G, Kjeldsen SE. Patients with treatment-resistant hypertension report increased stress and anxiety: a worldwide study. J Hypertens. 2013; 31(3):610-615.

5. Daugherty SL, Powers JD, Magid DJ, et al. The association between medication adherence and treatment intensification with blood pressure control in resistant hypertension. Hypertension. 2012; 60(2):303-309.

6. Shimbo D, Levitan EB, Booth JN III, et al. The contributions of unhealthy lifestyle factors to apparent resistant hypertension. J Hypertens. 2013; 31(2):370-376.

7. Gaddam KK, Nishizaka MK, Pratt-Ubunama MN, et al. Characterization of resistant hypertension: association between resistant hypertension, aldosterone, and persistent intravascular volume expansion. Arch Intern Med. 2008; 168(11):1159-1164.

8. de Faria AP, Demacq C, Figueiredo VN, et al. Hypoadiponectinemia and aldosterone excess are associated with lack of blood pressure control in subjects with resistant hypertension. Hypertens Res. 2013; 36(12):10671072.

9. de la Sierra A, Segura J, Banegas JR, et al. Clinical features of 8295 patients with resistant hypertension classified on the basis of ambulatory blood pressure monitoring. Hypertension. 2011; 57 (5):898-902.

10. Pierdomenico SD, Lapenna D, Bucci A, et al. Cardiovascular outcome in treated hypertensive patients with responder, masked, false resistant, and true resistant hypertension. Am J Hypertens. 2005; 18(11):1422-1428.

11. Franklin SS, Thijs L, Hansen TW, et al. International Database on Ambulatory Blood Pressure in Relation to Cardiovascular Outcomes
Investigators. Significance of white-coat hypertension in older persons with isolated systolic hypertension. Hypertension. 2012; 59(3):564-571.

12. Muxfeldt ES, Fiszman R, de Souza F, Viegas B, Oliveira FC, Salles GF. Appropriate time interval to repeat ambulatory blood pressure monitoring in patients with white-coat resistant hypertension. Hypertension. 2012; 59(2):384-389.

13. Zeller A, Schroeder K, Peters TJ. An adherence self-report questionnaire facilitated the differentiation between nonadherence and nonresponse to antihypertensive treatment. J Clin Epidemiol. 2008; 61(3):282-288.

14. Lee JY, Kusek JW, Greene PG, et al. Assessing medication adherence by pill count and electronic monitoring in the African American Study of Kidney Disease and Hypertension (AASK) Pilot Study. Am J Hypertens. 1996; 9(8):719-725.

15. van Onzenoort HA, Verberk WJ, Kessels AG, et al. Assessing medication adherence simultaneously by electronic monitoring and pill count in patients with mild-to-moderate hypertension. Am J Hypertens. 2010; 23(2):149-154.

16. Strauch B, Petrák $O$, Zelinka $T$, et al. Precise assessment of noncompliance with the antihypertensive therapy in patients with resistant hypertension using toxicological serum analysis. J Hypertens. 2013; 31(12):2455-2461.

17. Brinker S, Pandey A, Ayers $C$, et al. Therapeutic drug monitoring facilitates blood pressure control in resistant hypertension. J Am Coll Cardiol. 2014; 63 (8):834-835.

18. Mancia G, Fagard R, Narkiewicz K, et al. Task Force Members. 2013 ESH/ESC Guidelines for the management of arterial hypertension. J Hypertens. 2013; 31(7):1281-1357.

19. Worsnop CJ, Naughton MT, Barter CE, Morgan TO, Anderson AI, Pierce RJ. The prevalence of obstructive sleep apnea in hypertensive. Am J Respir Crit Care Med. 1998; 157(1):111-115.

20. Pedrosa RP, Drager LF, Gonzaga CC, et al. Obstructive sleep apnea: the most common secondary cause of hypertension associated with resistant hypertension. Hypertension. 2011; 58(5): 811-817.

21. Umpierrez GE, Cantey P, Smiley D, et al. Primary aldosteronism in diabetic subjects with resistant hypertension. Diabetes Care. 2007; 30(7): 16991703.

22. Sang $X$, Jiang $Y$, Wang $W$, et al. Prevalence of and risk factors for primary aldosteronism among patients with resistant hypertension in China. J Hypertens. 2013; 31(7):1465-1471.

23. Funder JW, Carey RM, Fardella C, et al. Endocrine Society. Case detection, diagnosis, and treatment of patients with primary aldosteronism: an endocrine society clinical practice guideline. J Clin Endocrinol Metab. 2008; 93(9):3266-3281.

24. Parthasarathy HK, Ménard J, White WB, et al. A double-blind, randomized study comparing the antihypertensive effect of eplerenone and spironolactone in patients with hypertension and evidence of primary aldosteronism. J Hypertens. 2011; 29(5):980-990.

25. Rossi GP, Cesari M, Cuspidi C, et al. Long-term control of arterial hypertension and regression of left ventricular hypertrophy with treatment of primary aldosteronism. Hypertension. 2013; 62(1): 62-69.

26. Lozano L, Tovar JL, Sampol G, et al. Continuous positive airway pressure treatment in sleep apnea patients with resistant hypertension: a randomized, controlled trial. J Hypertens. 2010; 28(10):2161-2168.

27. Trinquart L, Mounier-Vehier C, Sapoval M, Gagnon N, Plouin PF. Efficacy of revascularization for renal artery stenosis caused by fibromuscular dysplasia: a systematic review and meta-analysis. Hypertension. 2010; 56(3):525-532.

28. Ritchie J, Green D, Chrysochou C, Chalmers N, Foley RN, Kalra PA. High-risk clinical presentations in atherosclerotic renovascular disease: prognosis and response to renal artery revascularization. Am J Kidney Dis. 2014; 63(2):186-197. 